Rhabdomyosarcoma (RMS) is the most frequent soft tissue sarcoma in children. It is localized in the head and neck region in $40 \%$ of cases. Treatment of RMS is complex, including multi-drug chemotherapy, radiotherapy and surgery. The progress that has been accomplished in oncology in recent decades significantly improved outcomes. The 5-year survival rate raised from $25 \%$ in 1970 to $73 \%$ in 2001, according to IRS-IV data. The outcome is influenced by primary tumor localization, clinical staging, histological tumor type and age at the moment of diagnosis. The relatively rare incidence of these tumors resulted in difficulties in creating more standardized therapeutic protocols. Comparison of outcomes in large patients groups led to an increase in the number of patients with complete remission. Although survival rates of RMS patients have improved, searching for new therapeutic modalities and substances is still essential to improve outcomes in cases of more advanced stages and unfavorable tumor localizations.

Key words: head and neck rhabdomyosarcoma, sarcoma, surgery, radiation therapy, chemotherapy.

Contemp Oncol (Pozn) 2015; 19 (2): 98-107 DOI: $10.5114 /$ wo.2015.49158

\section{Rhabdomyosarcoma of the head and neck in children}

\author{
Joanna Radzikowska', Wojciech Kukwa', Andrzej Kukwa², Anna Czarnecka ${ }^{3}$, \\ Antoni Krzeski ${ }^{1}$
}

1Department of Otorhinolaryngology, Faculty of Medicine and Dentistry, Medical University of Warsaw, Warsaw, Poland

2Department of Otolaryngology and Head and Neck Disease, University of Warmia and Masuria School of Medicine, Olsztyn, Poland

3Laboratory of Molecular Oncology, Department of Oncology, Military Institute of Medicine, Warsaw, Poland

\section{Introduction}

Malignant tumors in childhood are relatively rare compared to adults, but despite the great progress in medicine, they are still the third cause of mortality in children, following trauma and intoxication [1].

Treatment and diagnosis of soft-tissue sarcomas is a challenging problem. They belong to one of the most rapidly proliferating tumors (duplication time of the tumor mass can be only 14 days). As they do not have a capsule, they may easily infiltrate surrounding tissues and distant organs by forming so-called skip lesions. They are characterized by frequent local relapse and high rate of early lung metastases. Progress that has been accomplished in oncology in the last three decades significantly improved outcomes. With regard to soft tissues sarcomas the 5 -year survival rate raised from $25 \%$ in 1970 to $73 \%$ in 2001, according to IRS-IV data [2, 3]. This progress results from introducing complex treatment based on modern aggressive chemotherapy, advanced radiologic imaging and still improving surgical techniques (especially in skull base surgery, microsurgery and reconstruction surgery). Multidisciplinary research groups are engaged in improving therapeutic protocols by creating patients databases, outcome analysis and registering adverse effects and inadvertent events. In Poland this is Polish Pediatric Solid Tumors Group which cooperates with corresponding groups in Europe and the rest of the world (e.g. German Cooperative Soft Tissue Sarcoma Group - CWS, International Society of Pediatric Oncology - SIOP, Italian Cooperative Group - ICG or Intergroup Rhabdomyosarcoma Study - IRS).

\section{Epidemiology and etiology}

Rhabdomyosarcoma accounts for $7 \%$ of malignant tumors in children and is the most frequent soft tissue sarcoma in children [4]. According to American data 350 new cases of RMS are registered each year in the United States [5]. Onset of the disease is at $2-5$ years of age. A significant rise in morbidity is registered in adolescents $>12$ years [4]. No evident geographic and ethnic correlations have been observed. However, Asians are less susceptible than white and black races. The incidence of RMS is about 1.5 times higher in boys than in girls. The incidence of RMS is also higher in children of mothers who have had a breast tumor [4]. The role of the risk factors in its pathogenesis has not been finally confirmed. The positive correlation between RMS and Recklinghausen disease [6], Li-Fraumeni syndrome [7], Costello [8], Noonan [9] or Beckwith-Wiedemann [10] syndromes suggests the role of genetic factors. It is also believed that the mother's exposure to cocaine and marihuana during pregnancy may have an impact on the disease onset [11]. 


\section{General characteristics}

Forty percent of RMS cases are manifested in the head and neck region. Localization of the primary tumor has a prognostic value and therefore it determines the therapeutic management strategy. Three tumor sites can be distinguished in the head and neck region: parameningeal, orbital and the third one - meaning the rest of structures in the head and neck region. 25\% of RMS are localized in the parameningeal region [12]. This group includes tumors of the nasal cavity, nasopharynx, paranasal sinuses, middle ear and skull base. They remain asymptomatic at early stages of the tumor growth and it is problematic to perform complete resection. First symptoms may be purulent and hematous secretions from the nose and ear, auricular duct and nasal duct blockage or dysphagia [13]. Symptoms that mimic chronic inflammation of the upper airway tract may delay proper diagnosis up to 3-4 weeks. Cranial nerve disorders or other neurologic symptoms that suggest skull base or central nervous system infiltration are an indication for urgent radiologic imaging. Presence of tumor cells in cerebrospinal fluid quite often precedes tumor radiologic signs in the central nervous system.

Nine percent of RMS are localized in the orbit [12]. Prognosis is better in this case, mainly because of early presence of tumor symptoms, e.g. exophthalmos, often associated with eye ball immobilization, tumorous thickening of one eyelid, periorbital ecchymosis or strabismus [13].

Remaining RMS of the head and neck are localized in epicranial aponeurosis, soft tissues of the neck, salivary glands, oral cavity, larynx, middle and lower pharynx, thyroid gland and cheeks.

Rhabdomyosarcoma proliferates very rapidly, infiltrating neighboring tissues and spreading to lymph nodes and distant organs, such as lungs, bones, bone marrow, central nervous system, liver and retroperitoneal space. Metastases to distant organs, especially lungs, occur statistically more often than to lymph nodes.

\section{Histology}

Rhabdomyosarcomas are small round blue cell tumors - malignant low-grade tumors, typical for children. These tumors are composed of small cells, with a large, round, hyperchromatic nucleus that stains to dark blue under the influence of hematoxylin and eosin.

The differential histopathologic diagnoses are neuroblastoma, Ewing sarcoma and lymphoma, being a challenge even for an experienced pathologist. Analysis of patients' data from the IRS program revealed that nearly $20 \%$ of RMS diagnoses were incorrect [14]. Three basic types of rhabdomyosarcomas [4, 15] can be distinguished and their differentiation determines the therapy:

- embryonal (ERMS) - the most frequent form (about $60 \%$ ), which usually occurs in the head and neck region, genitourinary tract and in the retroperitoneal region; apart from the classical embryonal form two subtypes can be distinguished - botryoid RMS (6-10\%) and fusocellular RMS;
- alveolar RMS (ARMS) - accounts for $20 \%$ of cases, is localized mainly in the extremities, trunk, perineum, perinasal sinuses;

- pleomorphic/adult RMS - children are not affected, typically localized in the extremities.

Tumor histology determines treatment outcomes. The best prognosis is associated with embryonal RMS.

Histology also determines the final diagnosis. Therefore, evaluation of each positive histological result in an appropriate reference centre is recommended. Pathologist's experience and doing extra immunohistochemical (searching for skeletal muscle antigens such as desmin, myoglobin, actin, vimentin with monoclonal antibodies) and molecular testing (which should be done routinely) are essential. Presence of actin myofilaments and desmin in electron microscope may be helpful to differentiate from other small round cell tumors.

\section{Molecular testing}

Research in molecular testing, which has been conducted for years, has led to identification of chromosom abnormalities characteristic for RMS. First of all DNA content in childhood RMS was defined as an important variable in predicting prognosis. DNA hyperdiploid and tetraploid rhabdomyosarcomas have a favorable prognosis, while DNA diploid and polyploid tumors have a poor prognosis [16]. Ploidy may also correlate with histologic subtype with embryonal histology most commonly being hyperdiploid and alveolar histology usually tetraploid [17]. More specific testing is helpful not only in diagnosing but also in monitoring the minimal residual disease. It may also help to create new, more effective treatment strategies in the future. Upon many abnormalities that have been identified, two translocations are pathognostic for RMS: $\mathrm{t}(2 ; 13)$ (q35;q14) and $t(1 ; 13)(p 36 ; q 14)$, which are observed in $80 \%$ of cases of ARMS $[18,19]$. As a result fusing proteins that are transcription factors with increased activity - accumulate in the cell. Fusing proteins initiate or enhance oncogenesis by influencing growth, mobility, differentiation and apoptosis of tumor cells [20,21]. Significantly worse prognosis of patients with known characteristic translocation has led to the differentiation of two ARMS types: more aggressive ARMSp (fusion gene-positive alveolar RMS) and less aggressive ARMSn (fusion gene-negative alveolar RMS) [22]. It was found that that ERMS and ARMS present completely different genetic abnormalities. Embryonal RMS is characterized by loss of heterozygosity on the short arm of chromosome 11 (11p15.5). This results in the inactivation of a tumor-suppressor gene. On the other hand ARMS in $80-85 \%$ has the chromosomal translocations ' $t(2 ; 13)(q 35 ; q 14)$ or $t(1 ; 13)(p 36 ; q 14)$. Among those $\mathrm{t}(2 ; 13)$ appears in almost $70 \%[23,24]$. It was further described that reported chromosomal translocations $\mathrm{t}(2 ; 13)$ (q35;q14) or $\mathrm{t}(1 ; 13)(\mathrm{p} 36 ; \mathrm{q} 14)$ result in PAX3/FOXO1 and PAX7/FOXO1 fusion genes expression. Generation of a chimeric fusion gene involves the $P A X 3$ gene located on chromosome 2 and a member of the fork-head family - FOXO1 gene (formerly FKHR) - located in chromosome 13. At the same time translocation $t(1 ; 13)$ involves another PAX fami- 
ly gene - PAX7 - located on chromosome 1 and the FOXO1 gene and is present in 10-15\% of cases of ARMS $[23,24]$. PAX/FOXO1 fusion gene status also influence prognosis with fusion-gene-negative ARMS patients having a prognosis similar to that of patients with ERMS. Further molecular analyses have shown that the gene expression profile of fusion-gene-negative ARMS is significantly similar to ERMS, but clearly distinguishable from fusion-gene-positive ARMS [25]. Comparison of the treatment outcomes of both RMS cytogenetic variants confirmed that presence of the mentioned translocations is the main factor responsible for the increased risk of ARMS recurrence [22]. Nevertheless overexpression of the fusion protein alone in primary myoblasts in vitro or in a mouse xenograft model is insufficient for tumorigenic transformation of myoblasts, but overexpression of IRIZIO (FAM193B - family with sequence similarity 193 , member $B$ ) is a down-stream regulator in this process [26]. PAX3-FKHR also activate the IGFI-R (insulin-like growth factor receptor) expression [27]. Insulin-like growth factor 1 receptor-mediated signaling was shown as essential for continued proliferation of RMS cells [28] and Igf1r overexpression induce MAPK activation and Her2 overexpression. At the same time Her2 forms heterodimers with IGF1R and stimulation with IGF2 leads to Her2 phosphorylation in a vicious circle [29]. Insulin-like growth factor 2 overexpression was observed in $80 \%$ of samples and was hypothesized to have an important role in this pathway in RMS biology [30]. At the same time co-expression of IGF-1R and ALK was detected in ERMS and ARMS and combined inhibition of both pathways with ALK inhibitor (NVP-TAE684, Novartis), and anti-IGF$1 R$ antibody (R1507, Roche) was shown to have synergistic cytotoxic effects on RMS cells [31]. Finally, the HMGA2 (minor groove DNA-binding factor high mobility group AThook 2) - IGFBP2 (insulin-like growth factor binding protein 2) - NRAS (neuroblastoma RAS viral oncogene homolog) signaling pathway was indicated pointed as a critical oncogenic driver in ERMS [32]. Rhabdomyosarcoma cases exhibiting N-myc amplification were identified as ARMS. $\mathrm{N}$-myc gene amplification, could be therefore useful as a prognostic factor for an unfavorable outcome [33]. The presence of the PAX3/7-FOXO1 fusion genes and high RMS proliferative capacity is also associated with high N-Myc levels [34].

The German Cooperative Soft Tissue Sarcoma Study (CWS) investigated p53, mdm-2, and Ki-67 in RMS and have found that $p 53$ and $m d m-2$ are expressed at low levels and would not show differences in expression between ERMS and ARMS, but metastatic tumors of ERMS show significantly higher expression of p53 [35]. Low prevalence of TP53 mutations and/or MDM2 amplifications in RMS suggests inactivation of p53 function by other mechanisms and remains to be elucidated [36]. Nevertheless, RMS tumors that develop in TP53 germline mutation carriers present usually non-alveolar, anaplastic histology [37]. Moreover, de novo germline TP53 mutations have been found in patients with RMS and RMS are often reported in patients with Li-Fraumeni syndrome (LFS) $[38,39]$. In particular the majority of RMS cases develop sporadically, but 10-30\% of children who develop RMS are later diagnosed with an underlying genetic risk factor. In LFS familial clustering of RMS and other soft tissue tumors in children is reported, with accompanying adrenocortical carcinomas and early-onset breast cancer in adults. Rhabdomyosarcoma has also been reported as associated with Beckwith-Wiedemann syndrome [10]. Beckwith-Wiedemann syndrome is further characterized by exomphalos, macroglossia, and macrosomia, increased risk of developing Wilms tumor, hepatoblastoma, and neuroblastoma. This fetal overgrowth syndrome is associated with abnormalities on 11p15 + the locus of the insulin-like growth factor II (IGFII) gene. Another syndrome associated with RMS is Costello's syndrome - an autosomal dominant disorder characterized by post natal growth retardation, coarse facial features, loose skin and developmental retardation, and increased risk of development of multiple solid tumors. There have been 15 cases of RMS reported in approximately 100 known children with Costello syndrome [40-42]. There are other syndromes in which RMS is a less common tumor, such as nevoid basal cell carcinoma syndrome (NBCCS), neurofibromatosis type 1 and Rubinstein-Taybi syndrome [6, 43, 44].

The comparative genomic hybridization $(\mathrm{aCGH})$ approach has been recently used in ERMS analysis and shed light on the molecular background of this disease. The authors have shown that ERMS develops in cells with inactivated p53, Rb and CDKN2A/B. At the same time FGFR4, Ras, and Hedgehog $(\mathrm{Hh})$ are overexpressed. In particular CDKN2A/B, a tumor suppressor gene, is deleted in the majority of cases. FGFR4, a tyrosine kinase receptor, is overexpressed in $20 \%$ of cases, while GLI1, a Hh-pathway transcription factor, is abnormally activated in more than $50 \%$ of cases and NF1, a tumor suppressor and inhibitor of Ras, is deleted in 15\% of patients with deletion of NF1 and activating Ras mutations mutually exclusive [45]. Moreover ERMS cells were compared with normal myoblasts and the Wnt/ $\beta$-catenin signaling pathway was shown to be down-regulated with activation of this pathway promoting myogenic differentiation. Survivin and Secreted frizzled-related protein 2 (sfrp2) were shown to be associated with this inhibition of the Wnt signaling pathway in ERMS [46].

Recently overexpression of mTOR and activation of its signaling pathway have been reported in RMS. Subsequently mTOR inhibitors - rapamycin, temsirolimus, everolimus - have been shown to be active against RMS cell lines in vitro and xenograft models. Moreover, bevacizumab, a monoclonal antibody against vascular endothelial growth factor (VEGF), has also shown activity in those experiments [25]. Unfortunately, although the epidermal growth factor receptor (EGFR) has been reported as overexpressed in RMS, in an ARMS mouse model erlotinib, an EGFR inhibitor, had no effect on tumor progression [47].

\section{Diagnosis}

Rhabdomyosarcoma diagnosis should based on the precise physical investigation, past medical history, radiological imaging, histology, laboratory and molecular tests. 
Differential diagnosis of head and neck RMS includes a broad spectrum of pathologies. In general, head and neck masses are classified as congenital, inflammatory and neoplastic (Table 1) [48]. It is crucial to distinguish the most commonly observed benign from malignant lesions. Every painless, especially tender and fixed mass that has been present for several weeks or has grown very rapidly should be suspected for malignancy. Physical examination of the head and neck region includes visualization and palpation of the face, scalp, oral cavity and pharyngeal structures, anterior and posterior rhinoscopy, microscopic ear examination, nasopharyngeal, hypopharyngeal and laryngeal endoscopy, evaluation of cranial nerve function, eye and lymph node examination. In special cases (especially in very small children, who do not cooperate during examination), sedation may be required. Physical examination of chest, abdomen, extremities and genitalia completes the diagnostic process. When malignancy is suspected, radiological evaluation and biopsy should be performed as quickly as possible.

Magnetic resonance imaging (MRI) with contrast is thought to be the basic radiological imaging in the diagnosis of RMS of the head and/or neck. It allows one to precisely localize and measure tumor size, evaluate local invasiveness, and visualize metastases to the lymph nodes as well as meninges and brain tissue infiltration. It is also used in the evaluation of residual tumor mass after surgery and in diagnosis of tumor recurrence. Computed tomography with a contrast is also of great value, especially in evaluation of bone infiltration in the facial cranium and neurocranium. Ultrasound might be helpful in evaluating neck lymph nodes. According to some reports positron emission tomography (PET) looks promising in imaging residual tumor mass [14]. In diagnosis of primary tumors PET is a supplementary investigation. However, some recent studies suggest that bone metastases and lymph node metastases may be superiorly detected by PET/CT $[49,50]$. Considering the fact that $15 \%$ of children with RMS already have distant metastases at the moment of diagnosis [51], it is essential to complete the diagnosis with chest radiograph and/or CT, skeletal scintigraphy, bone marrow biopsy or trepanobiopsy from two sites and abdomen ultrasound or CT. Patients with possible intracranial infiltration should also undergo cytologic testing of the cerebrospinal fluid.

\section{Staging}

The decision about the appropriate therapeutic protocol for RMS is preceded by a complex classification process that includes clinical staging and evaluation of the completeness of the primary surgical procedure. Only on that basis is it possible to estimate the risk of tumor recurrence.

\section{Clinical evaluation}

The TNM-classification is used for clinical staging of the RMS. This classification includes tumor size, its primary localization, infiltration of the surrounding tissues, lymph nodes involvement and presence of distant metastases. Primary tumor localization determines the prognosis. Therefore, favorable and unfavorable localizations can be distinguished. Tumors that infiltrate the nasal cavity, nasopharynx, paranasal sinuses, middle ear, subtemporal fossa and pterygopalatine fossa (all these structures belonging to the parameningeal region) and urinary bladder, kidneys, prostate and extremities are unfavorable localizations. Favorable localizations include the orbit, each site in the head and neck that is not in the parameningeal region, as well as genitourinary organs (excluding urinary bladder and prostate) and bile duct. Clinical staging is presented in detail in Table 2 [14, 52, 53].

\section{Surgical classification}

The next step in the staging process of RMS is surgical classification that includes extent and radicality of the primary surgical procedure. The surgical margin of a tissue sample and dissected lymph nodes undergo histopathological evaluation. The basics of surgical evaluation are shown in Table 3 [14, 54, 55].

According to the data from IRS clinical research, the tumor advancement in nearly half of the patients at the moment of diagnosis did not allow for complete primary

Table 1. Differential diagnosis of pediatric head and neck masses

$\begin{array}{lll}\text { Congenital masses } & \text { Inflammatory masses } & \text { Neoplastic masses } \\ \text { Thyroglossal cyst } & \text { Reactive lymphadenopathy } & \text { Benign } \\ \text { Branchial cleft cyst } & \text { Bacterial or viral adenopathy } & \text { lipoma } \\ \text { Vascular tumor } & \text { Granulomatous diseases } & \text { fibroma } \\ \text { Dermoid cyst } & \text { tuberculosis } & \text { neurofibroma } \\ \text { Teratoma } & \text { toxoplasmosis } & \text { thyroid nodule } \\ \text { Bronchogenic cyst } & \text { sarcoidosis } & \text { salivary gland tumor } \\ \text { Thymic cyst } & \text { histoplasmosis } & \text { Malignant } \\ \text { Laryngocele } & \text { cat scratch disease } & \text { lymphoma (Hodgkin's disease, non-Hodgkin's } \\ & \text { Others } & \text { lymphoma) } \\ & \text { Sialadenitis } & \text { neural tumors (neurobalstoma, retinoblastoma) } \\ & \text { thyroid malignancies } \\ & \text { soft tissue sarcomas (RMS, non-RMS) } \\ & \text { nasopharyngeal carcinoma } \\ & \text { salivary gland malignancies } \\ & & \text { metastatic disease }\end{array}$


Table 2. TNM pretreatment staging classification for IRS-IV

\begin{tabular}{|c|c|c|c|c|c|}
\hline Stage & Sites & $\mathrm{T}$ & Size & $\mathrm{N}$ & $M$ \\
\hline 1 & favorable & $\mathrm{T}_{1}$ or $\mathrm{T}_{2}$ & $a$ or b & $\mathrm{N}_{0} \operatorname{or} \mathrm{N}_{1}$ or $\mathrm{N}_{\mathrm{x}}$ & $M_{0}$ \\
\hline 2 & unfavorable & $\mathrm{T}_{1}$ or $\mathrm{T}_{2}$ & a & $N_{0}$ or $N_{x}$ & $M_{0}$ \\
\hline 3 & unfavorable & $\mathrm{T}_{1}$ or $\mathrm{T}_{2}$ & $\begin{array}{l}a \\
b\end{array}$ & $\mathrm{~N}_{0}$ or $\mathrm{N}_{1}$ or $\mathrm{N}_{\mathrm{x}}$ & $\begin{array}{l}M_{0} \\
M_{0}\end{array}$ \\
\hline 4 & all & $\mathrm{T}_{1}$ or $\mathrm{T}_{2}$ & $a$ or b & $\mathrm{N}_{0}$ or $\mathrm{N}_{1}$ or $\mathrm{N}_{\mathrm{x}}$ & $M_{1}$ \\
\hline
\end{tabular}

$T_{1}$ - confined to anatomic site of origin; $T_{2}$ - extension and/or fixation to surrounding tissue; $a-\leq 5 \mathrm{~cm}$ in diameter in size; $b->5 \mathrm{~cm}$ in diameter in size; $N_{0}$ - regional nodes not clinically involved; $N_{1}$ - regional nodes clinically involved; $N_{x}$ - clinical status of regional nodes unknown; $M_{0}-$ no distant metastasis; $M_{1}$ - distant metastasis present (includes positive cytology in CSF, pleural, or peritoneal fluid, implants on pleural or peritoneal surface).

Table 3. Clinical grouping classification for RMS

$\begin{array}{ll}\text { Group } & \text { Extent of disease or surgical result } \\ \text { I(A) } & \text { Localized tumor, completely resected, regional nodes not involved } \\ \text { I(B) } & \text { - confined to site of origin } \\ \text { II } & \text { - infiltrating beyond site of origin } \\ \text { II(A) } & \text { - localized tumor, grossly resected with microscopic residual disease } \\ \text { II(B) } & \text { - regional disease with involved nodes, completely resected } \\ \text { II(C) } & \text { - regional disease, gross total resection but with microscopic residual disease } \\ \text { III(A) } & \text { Gross residual disease after biopsy only } \\ \text { III(B) } & \text { Gross residual disease after major resection ( } \geq 50 \% \text { debulking) } \\ \text { IV } & \text { Distant metastatic disease at onset, irrespective of surgical approach to primary tumor }\end{array}$

resection or the surgical procedure was limited only to the biopsy (group III).

\section{Risk stratification}

Prognosis in RMS is influenced by primary tumor site, stage, node status, clinical group which describes radicality of the primary surgical treatment, age and histological findings $[56,57]$. Unfavourable prognostic factors are parameningeal localization, alveolar histological subtype, age under 1 year and above 10, incomplete surgical resection before introduction of the systemic treatment and infiltration of regional lymph nodes [56].

Identification of independent risk factors that can modify prognosis resulted in the risk stratification system, which determines the appropriate therapeutical protocol individually for each patient. European and American risk stratification systems are slightly different. According to the guidelines of Children's Oncology Group (COG, formerly known as IRS) three risk groups can be distinguished: low-, intermediate- and high-risk group (Table 4) [58, 59].

Table 4. Evaluation of the tumor recurrence risk (COG)

$\begin{array}{llcc}\text { Risk groups } & \text { Histology } & \text { Stage } & \begin{array}{c}\text { Clinical } \\ \text { group }\end{array} \\ \text { Low risk } & \text { embryonal RMS } & 1 & \text { I, II, III } \\ & \text { embryonal RMS } & 2,3 & \text { I, II } \\ \text { Intermediate } & \text { embryonal RMS } & 2,3 & \text { III } \\ \text { risk } & \text { alveolar RMS } & 1,2,3 & \text { I, II, III } \\ \text { High risk } & \text { embryonal RMS } & 4 & \text { IV } \\ & \text { alveolar RMS } & 4 & \text { IV }\end{array}$

The low-risk group includes patients with nonmetastatic disease of favorable histology at a favorable site or at an unfavorable site but completely resected. Patients with gross residual disease at orbital localization are also included in this group. Low-risk patients have the best prognosis (estimated survival rate is $85 \%$ to 95\%) [56]. Intermediate-risk patients are defined as patients with a localized disease and unfavorable histology as well as all stage 2 and 3 group III patients, regardless of histology. Results of the analysis done by Arndt et al. confirm that 4-year EFS in this group was $73 \%$ to $68 \%$ for two different treatment regimens [60]. The high-risk group includes all patients with metastatic disease. Estimated 3-year OS and 3 -year EFS are 34\% and 27\%, respectively [61].

In contrast to the American system, the European risk stratification system, proposed by the European Pediatric Soft Tissue Sarcoma Group (EpSSG), distinguishes 4 risk groups for localized RMS: low, standard, high and veryhigh risk groups (Table 5). Patients with metastatic disease are considered separately. The European system also includes the age factor ( $\leq 10$ years and $>10$ years). Furthermore, patients with localized RMS and clinically confirmed lymph node infiltrations are automatically assigned to the high or very-high risk group (depending on histological findings).

Regarding results of the recently conducted analysis of surveillance in the alveolar RMS depending on the PAX/ FOXO1 fusion status, it seems that actual risk stratification system should be verified [62].

\section{Treatment and prognosis}

The actual treatment strategy for RMS of the head and neck is an effect of the revolution in the last 30 years. Until 
Table 5. Risk stratification of localized RMS (CWS)

\begin{tabular}{|c|c|c|c|c|c|}
\hline Risk group & Histology & Clinical group & Site & $\mathrm{N}$ & Size \& age \\
\hline Low & embryonal RMS & I & any & NO & $\leq 5 \mathrm{~cm}$ and $\leq 10$ years \\
\hline \multirow{3}{*}{ Standard } & embryonal RMS & । & any & NO & $>5$ or $>10$ years \\
\hline & embryonal RMS & II, III & favorable & NO & any \\
\hline & embryonal RMS & II, III & unfavorable & NO & $\leq 5 \mathrm{~cm}$ and $\leq 10$ years \\
\hline \multirow{3}{*}{ High } & embryonal RMS & II, III & unfavorable & NO & $>5$ or $>10$ years \\
\hline & embryonal RMS & II, III & any & $\mathrm{N} 1$ & any \\
\hline & alveolar RMS & I, II, III & any & NO & any \\
\hline Very high & alveolar RMS & II, III & any & N1 & any \\
\hline
\end{tabular}

the early 1960s the gold standard was a primary surgical procedure in every case of RMS, followed by radiation therapy (in case of lack of complete surgical resection). Therefore it is not surprising that the survival rate was $5-9 \%$. The real breakthrough was implementation of the first chemotherapeutics.

Long-term comparative analysis of study results (on large groups of patients) helped to create new complex treatment that is composed of multi-drug chemotherapy, radiation therapy and surgery. This strategy has significantly improved the prognosis of most patients. According to American data the overall 5-year survival rate is now $73 \%$ [63]. European statistics are similar (the 5 -year survival rate is 69-71\%) [63]. Unfortunately, data about children that already have distant metastases at the moment of diagnosis are still more pessimistic. This group accounts for $15 \%$ of all pediatric patients with RMS and their prognosis has not improved much for more than 15 years $[51,61,64]$. The 5-year survival rate is only 20-30\% [51, 64-66].

Patients with recurrent tumor are also very challenging. Although temporal complete remission after second line treatment is possible, chances for complete recovery are poor $[67,68]$. An unfavorable prognostic factor is a short time between the end of first-line treatment and tumor recurrence [69]. According to CWS reports, five-year postrelapse survival is only $24 \%$ [70].

The appropriate treatment protocol is individual depending on the risk factors such as primary tumor localization, staging, histology, as well as age and general condition of the patient.

\section{Chemotherapy}

Chemotherapy is a basic treatment for RMS. The most active substances against rhabdomyosarcoma cells are vincristine, cyclophosphamide, actinomycin D, doxorubicin, isophosphamide and etoposide. The combination of these drugs and their dosage depend on many factors, such as risk group, histologic type, completeness of the primary resection as well as age and general condition of the child [71]. Treatment protocols are created and modified by research groups. Polish oncologic centers use CWS therapeutic protocols, which are recommended by the Polish Pediatric Solid Tumors Group.
An alternative method, reserved especially for patients with disseminated tumor disease (group IV) with the worst prognosis, is aggressive chemotherapy with subsequent autologous myogenic stem cell transplantation [72, 73].

\section{Radiation therapy}

Radiation therapy, apart from surgery, is a basic method for local tumor control. The starting point, its schema and total radiation dosage are individualized according to the therapeutic protocols. Taking into account that only $15 \%$ of all RMS patients accomplish complete recovery (group I), radiation therapy is used in most cases. Cessation or delay of radiation therapy is related to increased risk of local tumor relapse. American and European specialists have slightly different attitudes to tumor local control, including radiation therapy. Chemotherapy is the basic treatment according to European protocols. Surgical treatment and radiation therapy (ultimately) are reserved for patients with an unsatisfactory outcome after the first-line treatment. According to American therapeutic protocols, surgery and radiation therapy are considered at earlier stages of treatment.

Radiation dosage is usually 36-50.4 Gy and is a compromise between the necessity of aggressive treatment and patient's safety. Smaller dose can be used in patients after microscopically incomplete surgery (group II). Patients with residual tumor and those with initially unresected tumor require greater doses. The real challenge for radiotherapeutists concerns children under the age of 3 , in whom the risk is significantly greater.

Because of many critical structures in the head and neck region late effects of irradiation are frequent. Rhabdomyosarcoma treatment toxicity can be divided into several categories: neuroendocrine dysfunction, intellectual and academic delays, vision, hearing and dental problems, facial asymmetry, thyroid dysfunction, second malignancies and others [74]. Among those facial asymmetry, neuroendocrine dysfunction (resulting in growth hormone deficiency), hypothyroidism, dental abnormalities and intellectual delay are chiefly attributed to irradiation [74]. However facial growth retardation and visual problems such as blindness, orbital hypoplasia, nasolacrimal duct obstruction could be secondary to both surgery and radiotherapy [74]. 
In order to increase the safety of radiation therapy, i.e. minimize the risk of radiation of healthy tissues surrounding the tumor, it is possible to apply conformal radiotherapy, intensity-modulated radiation therapy (IMRT) and proton therapy $[75,76]$. Very promising are reports about effectiveness of brachytherapy in the treatment of sarcomas. It has been evidenced that the radiation dose applied directly to the tumor removal site is associated with fewer complications in comparison with conventional teleradiotherapy. High effectiveness of that method has been proved in the treatment of RMS of the genitourinary tract and extremities. In relation to RMS of the head and neck the outcome has not been evaluated as the number of case reports is still insufficient $[13,77,78]$.

\section{Surgery}

Surgical treatment of RMS is an important component of the complex management strategy as complete resection (RO - with a margin of minimum $1 \mathrm{~cm}$ microscopically free of tumor cells) has the best prognosis. However, it is extremely difficult to achieve that margin of tumor-free tissues in the head and neck region due to its anatomical structure. In addition, the RMS of the head and neck is already locally advanced in nearly $50 \%$ of patients at the moment of diagnosis [79]. Therefore if the surgical procedure cannot be radical or the risk of mutilation and loss of function is very high, chemotherapy will be the first step and surgical intervention will be limited only to the biopsy. The biopsy should be done in accordance with oncologic "sterility" (small incision along natural body lines, taking into account the future surgery; large amount of the specimen, including tumor-healthy tissue border). Furthermore, clinically suspected lymph nodes should always be verified by the histopathologist in the first place [71]. Patients who are excluded from the primary tumor resection may undergo second-look surgery (delayed resection of the residual tumor) after receiving induction chemotherapy or chemoradiotherapy. Functional and cosmetic results of the procedure must also be taken into consideration in that case.

Surgical procedures of the head and neck region, especially in the perimeningeal localization, are technically difficult. They frequently involve a multidisciplinary team of specialists: laryngologists, neurosurgeons, maxillo-facial and plastic surgeons. The operating room should be equipped with a microscope, endoscopy devices and neuronavigation. Surgical access should be wide enough to enable good visualization of the tumor mass on one hand, and on the other include future reconstruction of the tissue defects. The following surgical accesses are used: anterior (lateral rhinotomy with partial maxillectomy), lateral (zygomatic-orbital craniotomy with possible condylotomy or facial nerve dissection with its reconstruction during the same procedure; pharyngotomy), frontal-orbital craniotomy and mixed (in the case of extensive tumors). The most common complications are paralysis of cranial nerves (most frequently of trigeminal and facial nerves), compromised motility of the temporo-mandibular joint and cosmetic defects.
Tumors of the orbital region require special attention. Better prognosis, due to favorable localization and embryonal tumor type, as well as high effectiveness of the chemoradiotherapy, causes that orbital exenteration is limited only to patients with residual or recurrent tumors.

\section{New treatment strategies}

Progress in immunology and genetics revealed new therapeutic modalities in oncology. In terms of conventional chemotherapy, intensification of chemotherapy for nonmetastatic ERMS provided no survival advantage but adds toxicity when the ifosfamide, vincristine, and dactinomycin (IVA) schedule was compared with the six-drug combination (IVA plus carboplatin, epirubicin, and etoposide) [80]. At the same time intravenous vinorelbine (VNL) and continuous low doses of oral cyclophosphamide (CPM) combination - VNL $25 \mathrm{mg} / \mathrm{m}^{2}$ on days 1,8 and 15 of each 28-day cycle combined with continuous daily oral CPM $25 \mathrm{mg} / \mathrm{m}^{2}$ showed an interesting response rate in RMS [81]. Moreover preliminary results of irinotecan and carboplatin administered with concurrent radiotherapy (in the range of 30.6-50.4Gy) in RMS demonstrated favorable tolerability, efficacy, and local control [82]. It has been proved in animal models that some antiangiogenic factors, such as antibodies against endothelial growth factor, can inhibit sarcoma cell growth. Furthermore, proteins that result from PAX and FKHR gene fusion may serve as RMS antigens for cytotoxic lymphocytes [13, 14, 83]. According to the latest reports, the oncolytic viruses HSV-1 [14, 84], oligopeptides CpG [14, 85] and rapamycin analogues [14, 86] may also be useful in RMS treatment. Temsirolimus administered weekly at the dose of $75 \mathrm{mg} / \mathrm{m}^{2}$ did not meet the primary objective efficacy end-point in RMS, but was later evaluated in combination therapy [87]. A phase 1 trial of temsirolimus in combination with irinotecan and temozolomide in children, adolescents and young adults with relapsed or refractory solid tumors has shown that combination of TEM (35 mg/m²/dose IV weekly), IRN (90 mg/ $\mathrm{m}^{2} /$ dose days $\left.1-5\right)$ and TMZ (125 mg/m²/dose days $\left.1-5\right)$ administered PO every 21 days is well tolerated in children [88]. Another phase 2 trial of cixutumumab of $9 \mathrm{mg} / \mathrm{kg}$ as a 1-hour IV infusion once weekly ended with partial response in $1 / 20$ RMS cases [89]. Simultaneous targeting of insulin-like growth factor-1 receptor (IGF-1R) and anaplastic lymphoma kinase (ALK) was suggested in ARMS, and a trial may be designed [31]. At the same time sorafenib and pazopanib - multityrosine kinase receptor inhibitors are approved for adult soft tissue sarcoma by the U.S. Food and Drug Administration, and phase I testing in children with RMS is now complete. Crizotinib was also investigated due to overexpression of anaplastic lymphoma kinase (ALK) in ARMS and it was shown that this drug is safe in children. Unfortunately, ALK overexpression in RMS is not common enough to justify a phase III trial. Moreover, vismodegib (hedgehog inhibitor) and alisertib (Aurora-kinase inhibitor) are in early development in RMS treatment research and TH-302 is under active investigation for adult STS in combination with doxorubicin and may be later investigated in children [90]. 


\section{Summary}

The treatment strategy for rhabdomyosarcomas of the head and neck involves strict multidisciplinary cooperation. The relatively rare incidence of these tumors resulted in formation of international research groups that developed more standardized therapeutic protocols. Comparison of outcomes in large patient groups led to an increase in the number of patients with complete remission. Although survival rates of RMS patients have improved, searching for new therapeutic modalities and substances is still essential to improve outcomes in cases of more advanced stages and unfavorable tumor localizations.

The authors declare no conflict of interest.

\section{References}

1. Murphy SL. Deaths: final data for 1998. Natl Vital Stat Rep 2000; 48: 1-105.

2. Zalewska-Szewczyk B, Kazanowska B, Młynarski W, et al. Analiza przebiegu klinicznego i wyników leczenia mięsaków tkanek miękkich w lokalizacji okołooponowej u dzieci leczonych zgodnie z programem CWS 96 - raport Polskiej Grupy Pediatrycznej Guzów Litych. Wspolczesna Onkol 2008; 12: 116-20.

3. Kazanowska B, Reich A, Reich M, et al. Remaining problems and controversies in the management of childhood head and neck soft tissue sarcomas: Retrospective (national) Multicenter Study of the Polish Pediatric Solid Tumors Group. Pediatr Hematol Oncol 2004; 21: 349-62.

4. Krzakowski M. Onkologia kliniczna. In: Woźniak W (ed.). Nowotwory lite u dzieci. $2^{\text {nd }}$ ed. Borgis, Warszawa 2006; 1401-3.

5. Ries LAG, Smith MA, Gurney JG, et al. Cancer incidence and survival among children and adolescents: United States. SEER Program 1975-1995. In: NIH Pub. No. 99-4649, Edition Bethesda, MD: National Cancer Institute, SEER Program 1999.

6. Sung L, Anderson JR, Arndt C, Raney RB, Meyer WH, Pappo AS. Neurofibromatosis in children with Rhabdomyosarcoma: a report from the Intergroup Rhabdomyosarcoma study IV. J Pediatr 2004; 144: 666-8.

7. Carnevale A, Lieberman E, Cárdenas R. Li-Fraumeni syndrome in pediatric patients with soft tissue sarcoma or osteosarcoma. Arch Med Res 1997; 28: 383-6.

8. O'Neal JP, Ramdas J, Wood WE, Pellitteri PK. Parameningeal rhabdomyosarcoma in a patient with Costello syndrome. J Pediatr Hematol Oncol 2004; 26: 389-92.

9. Jung A, Bechthold S, Pfluger T, Renner C, Ehrt O. Orbital rhabdomyosarcoma in Noonan syndrome. J Pediatr Hematol Oncol 2003; 25: 330-2.

10. Smith AC, Squire JA, Thorner P, et al. Association of alveolar rhabdomyosarcoma with the Beckwith-Wiedemann syndrome. Pediatr Dev Pathol 2001; 4: 550-8.

11. Grufferman S, Schwartz AG, Ruymann FB, Maurer HM. Parents' use of cocaine and marijuana and increased risk of rhabdomyosarcoma in their children. Cancer Causes Control 1993; 4: 217-224.

12. Crist WM, Anderson JR, Meza JL, et al. Intergroup rhabdomyosarcoma study-IV: results for patients with nonmetastatic disease. J Clin Oncol 2001; 19: 3091-102.

13. Pietniczka-Załęska M. Rhabdomyosarcoma głowy i szyi u dzieci. Magazyn Otorynolaryngologiczny 2006; suppl X: 30-6.

14. Breitfeld PP, Meyer WH. Rhabdomyosarcoma: new windows of opportunity. Oncologist 2005; 10: 518-27.

15. Kumar V, Cotran R, Robbins S. Patologia Robbinsa. In: Burns D (ed.). Układ mięśniowo-szkieletowy. $1^{\text {st }}$ ed. Urban \& Partner, Warszawa 2005; 896-7.

16. San Miguel-Fraile P, Carrillo-Gijón R, Rodriguez-Peralto JL, Badiola IA. Prognostic significance of DNA ploidy and proliferative index
(MIB-1 index) in childhood rhabdomyosarcoma. Am J Clin Pathol 2004; 121: 358-365.

17. Kilpatrick SE, Teot LA, Geisinger KR, Martin PL, Shumate DK, Zbieranski N, Russell GB, Fletcher CD. Relationship of DNA ploidy to histology and prognosis in rhabdomyosarcoma. Comparison of flow cytometry and image analysis. Cancer 1994; 74: 3227-33.

18. Galili N, Davis RJ, Fredericks WJ, Mukhopadhyay S, Rauscher FJ 3rd, Emanuel BS, Rovera G, Barr FG. Fusion of a fork head domain gene to PAX3 in the solid tumour alveolar rhabdomyosarcoma. Nat Genet 1993; 5 : 230-5.

19. Davis RJ, D'Cruz CM, Lovell MA, Biegel JA, Barr FG. Fusion of PAX7 to FKHR by the variant $t(1 ; 13)(p 36 ; q 14)$ translocation in alveolar rhabdomyosarcoma. Cancer Res 1994; 54: 2869-72.

20. Fredericks WJ, Galili N, Mukhopadhyay S, Rovera G, Bennicelli J, Barr FG, Rauscher FJ 3rd. The PAX3-FKHR fusion protein created by the $t(2 ; 13)$ translocation in alveolar rhabdomyosarcomas is a more potent transcriptional activator than PAX3. Mol Cell Biol 1995; 15: 1522-35.

21. Marcinkowska A. Rhabdomyosarcoma-zmiany genetyczne w patogenezie nowotworu. Nowotwory Journal of Oncology 2003; 53 : 286-92.

22. Williamson D, Missiaglia E, de Reyni s A, et al. Fusion gene-negative alveolar rhabdomyosarcoma is clinically and molecularly indistinguishable from embryonal rhabdomyosarcoma. J Clin Oncol 2010; 28: 2151-8.

23. De Giovanni C, Landuzzi L, Nicoletti G, Lollini PL, Nanni P. Molecular and cellular biology of rhabdomyosarcoma. Future Oncol 2009; 5: 1449-75.

24. Gallego Melcón S, Sánchez de Toledo Codina J. Molecular biology of rhabdomyosarcoma. Clin Transl Oncol 2007; 9: 415-9.

25. Malempati S, Hawkins DS. Rhabdomyosarcoma: review of the Children's Oncology Group (COG) Soft-Tissue Sarcoma Committee experience and rationale for current COG studies. Pediatr Blood Cancer 2012; 59: 5-10.

26. Picchione F, Pritchard C, Lagutina I, Janke L, Grosveld GC. IRIZIO: a novel gene cooperating with PAX3-FOXO1 in alveolar rhabdomyosarcoma (ARMS). Carcinogenesis 2011; 32: 452-61.

27. Ayalon D, Glaser T, Werner H. Transcriptional regulation of IGF-I receptor gene expression by the PAX3-FKHR oncoprotein. Growth Horm IGF Res 2001; 11: 289-97.

28. Dilling MB, Dias P, Shapiro DN, Germain GS, Johnson RK, Houghton PJ. Rapamycin selectively inhibits the growth of childhood rhabdomyosarcoma cells through inhibition of signaling via the type I insulin-like growth factor receptor. Cancer Res 1994; 54: 903-7.

29. Abraham J, Prajapati SI, Nishijo K, et al. Evasion mechanisms to Igf1r inhibition in rhabdomyosarcoma. Mol Cancer Ther 2011; 10: 697-707.

30. de Souza RR, Oliveira ID, Caran EM, Alves MT, Abib S, Toledo SR. Investigation of PAX3/7-FKHR fusion genes and IGF2 gene expression in rhabdomyosarcoma tumors. Growth Horm IGF Res 2012; 22: $245-9$.

31. van Gaal JC, Roeffen MH, Flucke UE, et al. Simultaneous targeting of insulin-like growth factor-1 receptor and anaplastic lymphoma kinase in embryonal and alveolar rhabdomyosarcoma: a rational choice. Eur J Cancer 2013; 49: 3462-70.

32. Li Z, Zhang Y, Ramanujan K, Ma Y, Kirsch DG, Glass DJ. Oncogenic NRAS, required for pathogenesis of embryonic rhabdomyosarcoma, relies upon the HMGA2-IGF2BP2 pathway. Cancer Res 2013; 73: 3041-50.

33. Hachitanda Y, Toyoshima S, Akazawa K, Tsuneyoshi M. N-myc gene amplification in rhabdomyosarcoma detected by fluorescence in situ hybridization: its correlation with histologic features. Mod Pathol 1998; 11: 1222-7.

34. Tonelli R, McIntyre A, Camerin C, et al. Antitumor activity of sustained $\mathrm{N}$-myc reduction in rhabdomyosarcomas and transcriptional block by antigene therapy. Clin Cancer Res 2012; 18: 796-807.

35. Leuschner I, Langhans I, Schmitz R, et al. p53 and mdm-2 expression in Rhabdomyosarcoma of childhood and adolescence: clinicopathologic study by the Kiel Pediatric Tumor Registry and the German Cooperative Soft Tissue Sarcoma Study. Pediatr Dev Pathol 2003; 6: 128-36. 
36. Ognjanovic S, Martel G, Manivel C, Olivier M, Langer E, Hainaut P. Low Prevalence of TP53 Mutations and MDM2 Amplifications in Pediatric Rhabdomyosarcoma. Sarcoma 2012; 2012: 492086.

37. Hettmer S, Archer NM, Somers GR, et al. Anaplastic rhabdomyo sarcoma in TP53 germline mutation carriers. Cancer 2014; 120 : 1068-75.

38. Magnusson S, Gisselsson D, Wiebe T, Kristoffersson U, Borg Olsson $\mathrm{H}$. Prevalence of germline TP53 mutations and history of Li-Fraumeni syndrome in families with childhood adrenocortical tumors, choroid plexus tumors, and rhabdomyosarcoma: a population-based survey. Pediatr Blood Cancer 2012; 59: 846-53.

39. Wozniak A, Fryer A, Grimer R, Mc Dowell H. Multiple malignancies in a child with de novo TP53 mutation. Pediatr Hematol Oncol 2011; 28: 338-43.

40. Menke J, Pauli S, Sigler M, et al. Uniparental Trisomy of a Mutated HRAS Proto-Oncogene in Embryonal Rhabdomyosarcoma of a Patient With Costello Syndrome. J Clin Oncol 2014 [Epub ahead of print].

41. Gripp KW, Scott CI Jr, Nicholson L, McDonald-McGinn DM, Ozeran JD, Jones MC, Lin AE, Zackai EH. Five additional Costello syndrome patients with rhabdomyosarcoma: proposal for a tumor screening protocol. Am J Med Genet 2002; 108: 80-7.

42. Sigaudy S, Vittu G, David A, Vigneron J, Lacombe D, Moncla A, Flor E, Philip N. Costello syndrome: report of six patients including one with an embryonal rhabdomyosarcoma. Eur J Pediatr 2000; 159 139-42.

43. Sobel RA, Woerner S. Rubinstein-Taybi syndrome and nasopharyngeal rhabdomyosarcoma. J Pediatr 1981; 99: 1000-1.

44. Lo Muzio L. Nevoid basal cell carcinoma syndrome (Gorlin syndrome). Orphanet J Rare Dis 2008; 3: 32

45. Paulson V, Chandler G, Rakheja D, Galindo RL, Wilson K, Amatruda JF, Cameron S. High-resolution array CGH identifies common mechanisms that drive embryonal rhabdomyosarcoma pathogenesis. Genes Chromosomes Cancer 2011; 50: 397-408.

46. Singh S, Vinson C, Gurley CM, et al. Impaired Wnt signaling in embryonal rhabdomyosarcoma cells from p53/c-fos double mutant mice. Am J Pathol 2010; 177: 2055-66.

47. Abraham J, Nelon LD, Kubicek CB, et al. Preclinical testing of erlotinib in a transgenic alveolar rhabdomyosarcoma mouse model. Sarcoma 2011; 2011: 130484.

48. Dickson PV, Davidoff AM. Malignant neoplasms of the head and neck. Semin Pediatr Surg 2006; 15: 92-8.

49. Dasgupta R, Rodeberg DA. Update on rhabdomyosarcoma. Semin Pediatr Surg 2012; 21: 68-78.

50. Evangelista L, Panunzio A, Polverosi R, Ferretti A, Chondrogiannis S, Pomerri F, Rubello D, Muzzio PC. Early bone marrow metastasis detection: the additional value of FDG-PET/CT vS. CT imaging. Biomed Pharmacother 2012; 66: 448-53.

51. Crist W, Gehan EA, Ragab AH, et al. The Third Intergroup Rhabdomyosarcoma Study. J Clin Oncol 1995; 13: 610-30.

52. Lawrence W Jr, Gehan EA, Hays DM, Beltangady M, Maurer HM. Prognostic significance of staging factors of the UICC staging system in childhood rhabdomyosarcoma: a report from the Intergroup Rhabdomyosarcoma Study (IRS-II). J Clin Oncol 1987; 5: 46-54.

53. Lawrence W Jr, Anderson JR, Gehan EA, Maurer H. Pretreatment TNM staging of childhood rhabdomyosarcoma: a report of the Intergroup Rhabdomyosarcoma Study Group. Children's Cancer Study Group. Pediatric Oncology Group. Cancer 1997; 80: 1165-70.

54. Maurer HM. The intergroup rhabdomyosarcoma study (NIH): Objectives and clinical staging classification. J Pediatr Surg 1975; 10: 977-8.

55. Maurer HM, Moon T, Donaldson M. The Intergroup Rhabdomyosarcoma Study: a preliminary report. Cancer 1977; 40: 2015-26.

56. Arndt CA. Risk stratification of rhabdomyosarcoma: a moving target. Am Soc Clin Oncol Educ Book 2013; 415-9.

57. Joshi D, Anderson JR, Paidas C, Breneman J, Parham DM, Crist W; Soft Tissue Sarcoma Committee of the Children's Oncology Group. Age is an independent prognostic factor in rhabdomyosarcoma: a report from the Soft Tissue Sarcoma Committee of the Children's Oncology Group. Pediatr Blood Cancer 2004; 42: 64-73.

58. Meza JL, Anderson J, Pappo AS, Meyer WH; Children's Oncology Group. Analysis of prognostic factors in patients with nonmeta- static rhabdomyosarcoma treated on intergroup rhabdomyosarcoma studies III and IV: the Children's Oncology Group. J Clin Oncol 2006; 24: 3844-51.

59. Gosiengfiao Y, Reichek J, Walterhouse D. What is new in rhabdomyosarcoma management in children? Paediatr Drugs 2012; 14 . 389-400.

60. Arndt CA, Stoner JA, Hawkins DS, et al. Vincristine, actinomycin, and cyclophosphamide compared with vincristine, actinomycin, and cyclophosphamide alternating with vincristine, topotecan, and cyclo phosphamide for intermediate-risk rhabdomyosarcoma: children's oncology group study D9803. J Clin Oncol 2009; 27: 5182-8.

61. Oberlin O, Rey A, Lyden E, Bisogno G, Stevens MC, Meyer WH, Carli $M$, Anderson JR. Prognostic factors in metastatic rhabdomyosarcomas: results of a pooled analysis from United States and European cooperative groups. J Clin Oncol 2008; 26: 2384-9.

62. Skapek SX, Anderson J, Barr FG, et al. PAX-FOXO1 fusion status drives unfavorable outcome for children with rhabdomyosarcoma: a children's oncology group report. Pediatr Blood Cancer 2013; 60: 1411-7.

63. Carroll W, Finlay J. Cancer in Children and Adolescents. In: Edition 1. Jones \& Bartlett Publishers 2009.

64. Breneman JC, Lyden E, Pappo AS, et al. Prognostic factors and clinical outcomes in children and adolescents with metastatic rhabdomyosarcoma - a report from the Intergroup Rhabdomyosarcoma Study IV. J Clin Oncol 2003; 21: 78-84.

65. Maurer HM, Beltangady M, Gehan EA, et al. The Intergroup Rhabdomyosarcoma Study-I. A final report. Cancer 1988; 61: 209-20.

66. Maurer HM, Gehan EA, Beltangady M, et al. The Intergroup Rhabdomyosarcoma Study-II. Cancer 1993; 71: 1904-1922.

67. Mazzoleni S, Bisogno G, Garaventa A, et al. Outcomes and prognostic factors after recurrence in children and adolescents with nonmetastatic rhabdomyosarcoma. Cancer 2005; 104: 183-90.

68. Pappo AS, Anderson JR, Crist WM, et al. Survival after relapse in children and adolescents with rhabdomyosarcoma: A report from the Intergroup Rhabdomyosarcoma Study Group. J Clin Oncol 1999; 17: 3487-93

69. Mattke AC, Bailey EJ, Schuck A, Dantonello T, Leuschner I, Klingebiel T, Treuner J, Koscielniak E. Does the time-point of relapse influence outcome in pediatric rhabdomyosarcomas? Pediatr Blood Cancer 2009; 52: 772-6.

70. Dantonello TM, Int-Veen C, Winkler P, et al. Initial patient characteristics can predict pattern and risk of relapse in localized rhabdomyosarcoma. J Clin Oncol 2008; 26: 406-13.

71. Kazanowska B, Chybicka A. Postępowanie diagnostyczno-terapeutyczne w nowotworach tkanek miękkich u dzieci. Onkologia w Praktyce Klinicznej 2007; 3: 680-98.

72. Admiraal R, van der Paardt M, Kobes J, Kremer LC, Bisogno G, Merks JH. High-dose chemotherapy for children and young adults with stage IV rhabdomyosarcoma. Cochrane Database Syst Rev 2010; CD006669.

73. Peinemann F, Kröger N, Bartel C, Grouven U, Pittler M, Erttmann R, Kulig M. High-dose chemotherapy followed by autologous stem cell transplantation for metastatic rhabdomyosarcoma - a systematic review. PLoS One 2011; 6: e17127.

74. Paulino AC, Simon JH, Zhen W, Wen BC. Long-term effects in children treated with radiotherapy for head and neck rhabdomyosarcoma. Int J Radiat Oncol Biol Phys 2000; 48: 1489-95.

75. Hug EB, Adams J, Fitzek M, De Vries A, Munzenrider JE. Fractionated, three-dimensional, planning-assisted proton-radiation therapy for orbital rhabdomyosarcoma: a novel technique. Int J Radiat Oncol Biol Phys 2000; 47: 979-84.

76. Yock T, Schneider R, Friedmann A, Adams J, Fullerton B, Tarbell N. Proton radiotherapy for orbital rhabdomyosarcoma: clinical outcome and a dosimetric comparison with photons. Int J Radiat Oncol Biol Phys 2005; 63: 1161-8.

77. Healey EA, Shamberger RC, Grier HE, Loeffler JS, Tarbell NJ. A 10 year experience of pediatric brachytherapy. Int J Radiat Oncol Biol Phys 1995; 32: 451-5.

78. Nag S, Tippin D, Ruymann FB. Long-term morbidity in children treated with fractionated high-dose-rate brachytherapy for soft tissue sarcomas. J Pediatr Hematol Oncol 2003; 25: 448-52. 
79. Turner JH, Richmon JD. Head and neck rhabdomyosarcoma: a critical analysis of population-based incidence and survival data. Otolaryngol Head Neck Surg 2011; 145: 967-73.

80. Oberlin O, Rey A, Sanchez de Toledo J, et al. Randomized comparison of intensified six-drug versus standard three-drug chemotherapy for high-risk nonmetastatic rhabdomyosarcoma and other chemotherapy-sensitive childhood soft tissue sarcomas: longterm results from the International Society of Pediatric Oncology MMT95 study. J Clin Oncol 2012; 30: 2457-65.

81. Minard-Colin V, Ichante JL, Nguyen L, et al. Phase II study of vinorelbine and continuous low doses cyclophosphamide in children and young adults with a relapsed or refractory malignant solid tumour: good tolerance profile and efficacy in rhabdomyosarcoma - a report from the Societe Francaise des Cancers et leucemies de l'Enfant et de l'adolescent (SFCE). Eur J Cancer 2012; 48: 2409-16.

82. Dharmarajan KV, Wexler LH, Wolden SL. Concurrent radiation with irinotecan and carboplatin in intermediate- and high-risk rhabdomyosarcoma: a report on toxicity and efficacy from a prospective pilot phase II study. Pediatr Blood Cancer 2013; 60: 242-7.

83. Dagher R, Long LM, Read EJ, et al. Pilot trial of tumor-specific peptide vaccination and continuous infusion interleukin-2 in patients with recurrent Ewing sarcoma and alveolar rhabdomyosarcoma: an inter-institute NIH study. Med Pediatr Oncol 2002; 38: 158-64.

84. Bharatan NS, Currier MA, Cripe TP. Differential susceptibility of pediatric sarcoma cells to oncolysis by conditionally replication-competent herpes simplex viruses. J Pediatr Hematol Oncol 2002; 24: 447-53.

85. Weigel BJ, Rodeberg DA, Krieg AM, Blazar BR. CpG oligodeoxynucleotides potentiate the antitumor effects of chemotherapy or tumor resection in an orthotopic murine model of rhabdomyosarcoma. Clin Cancer Res 2003; 9: 3105-14.

86. Hosoi H, Dilling MB, Shikata T, et al. Rapamycin causes poorly reversible inhibition of mTOR and induces p53-independent apoptosis in human rhabdomyosarcoma cells. Cancer Res 1999; 59: 886-94.

87. Geoerger B, Kieran MW, Grupp S, et al. Phase II trial of temsirolimus in children with high-grade glioma, neuroblastoma and rhabdomyosarcoma. Eur J Cancer 2012; 48: 253-62.

88. Bagatell R, Norris R, Ingle AM, et al. Phase 1 trial of temsirolimus in combination with irinotecan and temozolomide in children, adolescents and young adults with relapsed or refractory solid tumors: a Children's Oncology Group Study. Pediatr Blood Cancer 2014; 61: 833-9.

89. Weigel B, Malempati S, Reid JM, et al. Phase 2 trial of cixutumum$a b$ in children, adolescents, and young adults with refractory solid tumors: a report from the Children's Oncology Group. Pediatr Blood Cancer 2014; 61: 452-6.

90. Ferguson M, Hingorani P, Gupta AA. Emerging molecular-targeted therapies in early-phase clinical trials and preclinical models. Am Soc Clin Oncol Educ Book 2013; 420-4.

\section{Address for correspondence}

\section{Joanna Radzikowska}

Department of Otorhinolaryngology

Faculty of Medicine and Dentistry

Medical University of Warsaw

19/25 Stepinska Street

00-739 Warsaw, Poland

e-mail: jwronska@poczta.onet.pl

Submitted: 5.11 .2013

Accepted: 9.06 .2014 